\title{
Demand for self-managed online telemedicine abortion in eight European countries during the COVID-19 pandemic: a regression discontinuity analysis
}

\author{
Abigail R A Aiken (D) , ${ }^{1}$ Jennifer E Starling, ${ }^{2}$ Rebecca Gomperts, ${ }^{3}$ \\ James G Scott, ${ }^{4}$ Catherine E Aiken ${ }^{5}$
}

- Additional material is published online only. To view, please visit the journal online (http://dx.doi.org/10.1136/ bmjsrh-2020-200880).

'LBJ School of Public Affairs, The University of Texas at Austin, Austin, Texas, USA

${ }^{2}$ The University of Texas at Austin, Austin, Texas, USA

${ }^{3}$ Women on Web, Amsterdam, The Netherlands

${ }^{4}$ Red McCombs School of Business, The University of Texas at Austin, Austin, Texas, USA ${ }^{5}$ University of Cambridge, Cambridge, UK

\section{Correspondence to}

Dr Abigail R A Aiken, LBJ School of Public Affairs, The University of Texas at Austin, Austin, TX 78713,USA; araa2@utexas.edu

Received 24 September 2020 Revised 9 December 2020 Accepted 16 December 2020

\section{A Check for updates}

(c) Author(s) (or their employer(s)) 2021. No commercial re-use. See rights and permissions. Published by BMJ.

To cite: Aiken ARA, Starling JE, Gomperts R, et al. BMJ Sex Reprod Health Published Online First: [please include Day Month Year]. doi:10.1136/ bmjsrh-2020-200880

\begin{abstract}
Objectives In most European countries, patients seeking medication abortion during the COVID-19 pandemic are still required to attend healthcare settings in person. We assessed whether demand for self-managed medication abortion provided by online telemedicine increased following the emergence of COVID-19.
\end{abstract}

Methods We examined 3915 requests for self-managed abortion to online telemedicine service Women on Web (WoW) between 1 January 2019 and 1 June 2020. We used regression discontinuity to compare request rates in eight European countries before and after they implemented lockdown measures to slow COVID-19 transmission. We examined the prevalence of COVID-19 infection, the degree of government-provided economic support, the severity of lockdown travel restrictions and the medication abortion service provision model in countries with and without significant changes in requests.

Results Five countries showed significant increases in requests to $\mathrm{WoW}$, ranging from $28 \%$ in Northern Ireland (97 requests vs 75.8 expected requests, $\mathrm{p}=0.001)$ to $139 \%$ in Portugal (34 requests vs 14.2 expected requests, $p<0.001)$. Two countries showed no significant change in requests, and one country, Great Britain, showed an $88 \%$ decrease in requests (1 request vs 8.1 expected requests, $p<0.001$ ). Among countries with significant increases in requests, abortion services are provided mainly in person in hospitals or abortion is unavailable and international travel was prohibited during lockdown. By contrast, Great Britain implemented a fully remote no-test telemedicine service.

\section{Key messages}

- Following the emergence of COVID-19, demand for self-managed medication abortion increased in countries where abortion is provided mainly in hospitals and where travel restrictions were most stringent.

- By contrast, in Great Britain, the one country that implemented fully remote no-test medication abortion services, demand for self-managed abortion declined almost to zero.

- Findings demonstrate the urgent need for policymakers to expand access to medication abortion by telemedicine.

Conclusion These marked changes in requests for self-managed medication abortion during the COVID-19 pandemic demonstrate demand for remote models of care, which could be fulfilled by expanding access to medication abortion by telemedicine.

\section{INTRODUCTION}

The COVID-19 pandemic has posed challenges for the provision of abortion care in Europe. Reallocation of resources, redeployment of staff and social distancing requirements introduced new barriers to in-person clinic visits. ${ }^{12}$

Countries differed in their policy responses to these new challenges. Great Britain authorised home use of mifepristone, and by doing so, changed the service delivery model for medication abortion to a fully remote no-test telemedicine service. People accessing medication 
abortion up to 10 weeks' gestation were able to consult with a provider by phone and have mifepristone and misoprostol mailed for home use, with no ultrasound or in-person tests required. ${ }^{3-5}$ France extended the ability to take abortion medications at home following an in-person visit with a healthcare professional from 7 weeks to 9 weeks of gestation. ${ }^{6}$ Germany allowed mandatory preabortion counselling to take place by phone or video teleconsult instead of in person. ${ }^{7}$ Portugal waived the usual required waiting period and allowed follow-up to be postponed or done by telemedicine, but in-person visits were still required for service provision. ${ }^{8}$ Hungary, which provides only surgical abortions, suspended almost all services as a result of a government ban on non-life saving procedures early in the pandemic. ${ }^{8}$ Overall, most European countries made few major changes to increase access to medication abortion and all but Great Britain continued to require at least one in-person visit to a provider, despite calls from human rights groups to prioritise patient safety and expand remote access. ${ }^{79}$

The economic downtown and rising unemployment across Europe in the wake of the pandemic may increase demand for abortion care at a time when it is even more difficult to access in the clinic setting. This situation raises the possibility of more abortions taking place outside the formal healthcare setting (ie, selfmanaged abortions). MSI Reproductive Choices estimates that an additional 2.7 million unsafe abortions will take place globally as a result of health service disruptions caused by the pandemic. ${ }^{10}$

However, not all abortions that take place outside the formal healthcare settings are unsafe. Self-managed medication abortion provided through online telemedicine services has been shown to be a safe and effective option, although it is not without potential legal risks. ${ }^{11} 12$ Using data from one such service, we assessed whether demand for online telemedicine abortion changed in eight European countries after stay-athome restrictions to slow the spread of COVID-19 were introduced.

\section{METHODS}

We obtained fully deidentified data from Women on Web (WoW), a non-profit organisation that provides self-managed medication abortion by telemedicine up to 10 weeks' gestation. ${ }^{13}$ The service is accessed via an online form, which directly populates the database from which our data were obtained. Submitted forms are screened by a doctor and if clinical eligibility criteria are met, mifepristone and misoprostol are sent by mail. In some countries, referrals are also made to local in-clinic services. A donation of $€ 70-90$ is requested to support the service, but may be waived or reduced in cases of financial hardship. Information and support are provided via email in 16 languages by a trained helpdesk team. People accessing the service consent to the fully anonymised use of their data for research purposes when submitting the online consultation form.

Our analytic sample includes eight countries: Germany, Hungary, Italy, Malta, the Netherlands, Northern Ireland, Portugal and Great Britain. WoW currently accepts online consultations from 20 countries in Europe. We excluded nine countries that had too few requests to reliably detect differences in request numbers between the 'before' and 'after' periods (ie, fewer than 10 expected requests in the 'after' period). We also excluded Spain because the Spanish government censored the WoW website during the study period and so no requests could be made, ${ }^{14}$ Poland because the number of requests made to WoW has been unstable since the beginning of 2020 and France because consultations have only been accepted since January 2020, meaning there were too few to calculate a baseline trend in requests.

We obtained the daily number of requests made to WoW from the eight countries in our sample between 1 January 2019 and 1 June 2020 (the last day on which lockdown measures were lifted in a country is included in the analysis). The location of each request was derived from country of residence information provided by the person making the request through the online consultation form. We excluded duplicate requests, which were identified as $>1$ request with the same information and location made within 12 hours. The number of requests from each country was analysed using a regression-discontinuity design where time is the running variable (also known as interrupted time series). ${ }^{15}$ We designated a 'before' period, which began on 1 January 2019 and ended on the date that each individual country's government issued their first 'stay-at-home' directive. The one exception was Germany, where the 'before' period began on 1 January 2020 because WoW did not accept consultations from Germany until late 2019. The 'after' period began the first day after the 'stay-at-home' directive was issued for each country and ended on the first day that the directives were eased in each country. 'Stay-at-home' directives were chosen as the threshold date defining the 'pre' and 'post' periods because the majority of European countries issued such a directive, which posed definitive limitations on population movement and activities. Of the countries included in our analytic sample, only Malta did not issue a population-wide directive and we instead used the date on which the Maltese government issued a directive to close public places. ${ }^{16}$

We fit a generalised linear model for each country's daily requests between 1 January 2019 (1 January 2020, for Germany) and the date of easing 'stay-athome' restrictions. The model incorporated a dummy variable for the 'before' versus 'after' period, representing a possible discontinuity at the day of the 'stayat-home' directive. The statistical significance of the discontinuity for each country was assessed using a 
likelihood ratio test to compare with a null model that did not include a dummy variable for the 'before' versus 'after' period. The null model was also used to generate Monte Carlo simulations for each country, which create a probability distribution of the expected requests in the 'after' period with no discontinuity. The observed requests line would be highly likely to lie within this probability distribution if there was no difference in requests between the 'before' and 'after' periods. We also calculated the percentage difference between observed and expected requests in the 'after' period as $100 \times($ actual-expected $) /$ expected and compared the null and regression discontinuity models via likelihood ratio tests. For Northern Ireland, both the null and discontinuity models also included a dummy variable indicating the period after 10 April 2020, because abortion services were authorised for the first time in Northern Ireland on this date. ${ }^{17}$

We also compiled information for each country on several metrics we hypothesised that could be related to demand for online abortion: stringency of 'stay-at-home' requirements; deaths due to COVID19; economic assistance provided by governments ${ }^{18}$ and abortion service provision before and during the pandemic. ${ }^{78}$ 19-21 We examined each of these metrics

\section{Countries with significant increase in requests}
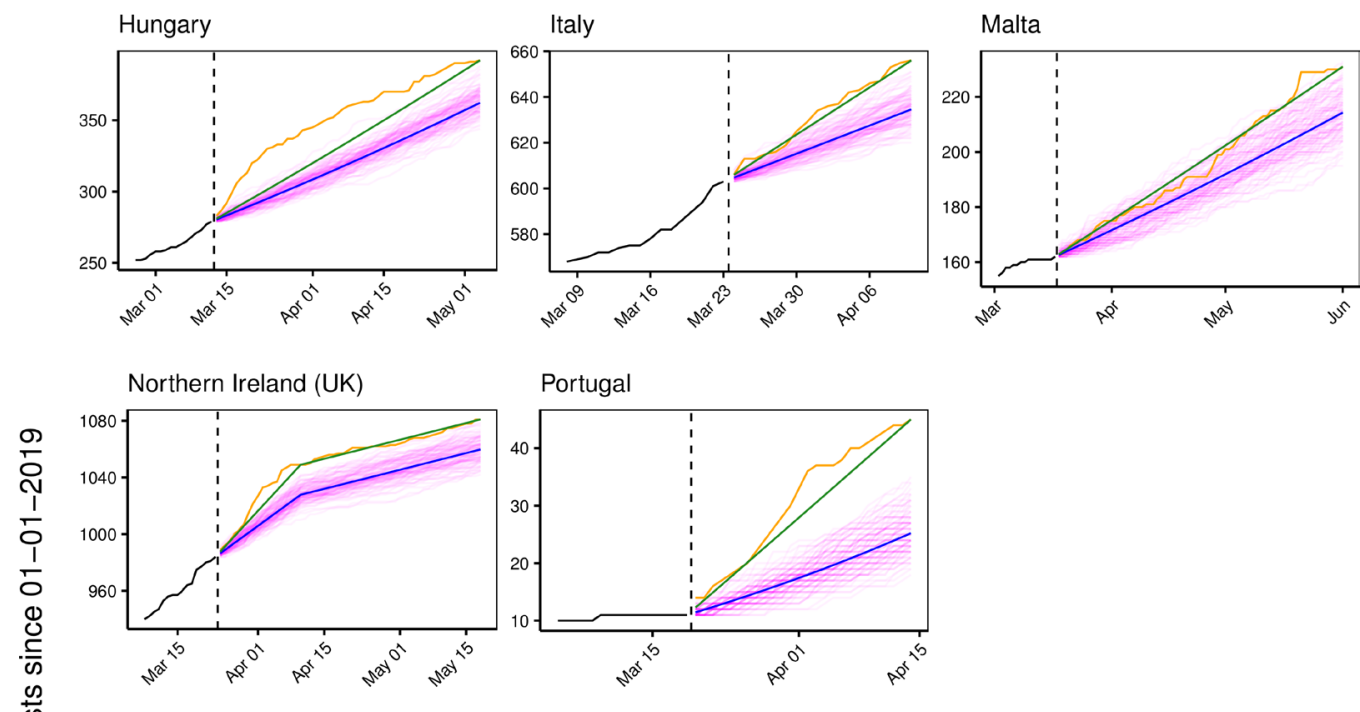

Countries without significant change in requests
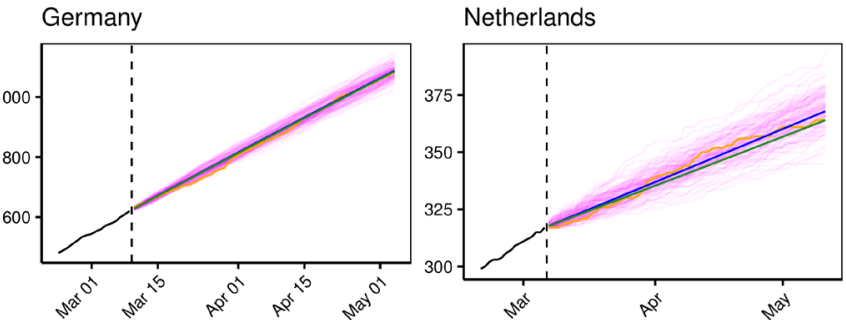

Countries with significant decrease in requests

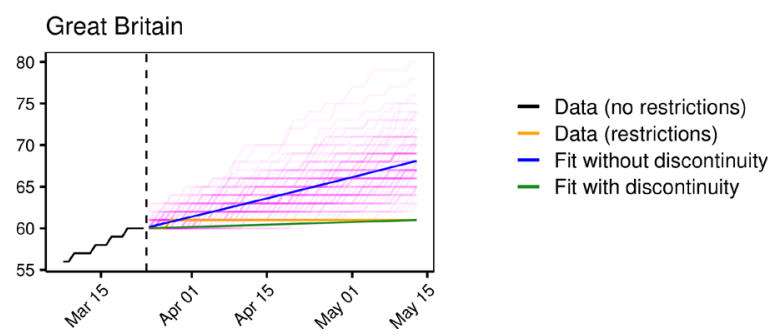

Figure 1 Observed versus expected requests to Women on Web for all countries included in the analysis. Cumulative requests in the 'before' versus 'after' periods are in black and orange, respectively. Vertical dashed lines show the dates when stay-at-home orders were announced. The blue line shows the model without any discontinuities (the null model), and the green line shows the model fit with a discontinuity. for the stay-at-home order. The pink lines are the 250 Monte Carlo simulations from the null model, which support the likelihood ratio test's finding that the model with discontinuities is a significantly better fit than the null model. 
across each country included in the analysis to assess their relationship to changes in requests to WoW.

Data analysis was conducted using the $\mathrm{R}$ statistical package V.3.6.2. ${ }^{22}$ Findings were considered statistically significant at an alpha level of 0.05 . The study was reviewed by the Institutional Review Board at The University of Texas at Austin and was considered exempt on the basis that the study is an analysis of precollected, fully deidentified data.

\section{Patient and public involvement}

No patients were involved in the design or conduct of the study.

\section{RESULTS}

During the data collection period, WoW received 3915 requests for abortion medications from the eight countries included in the analysis. Among these, we observed a statistically significant increase in requests during the 'after' period in five countries: Hungary, Italy, Malta, Portugal and Northern Ireland (figure 1). The magnitude of the observed increases ranged from $139 \%$ above expected in Portugal to $28 \%$ above expected in Northern Ireland (table 1). In two countries (Germany, the Netherlands), there was no statistically significant difference in observed numbers compared with expected numbers of requests in the 'after' period (figure 1 and table 1). In one country (Great Britain), there was a statistically significant decrease in requests in the 'after' period (figure 1 and table 1).

Countries which had higher numbers of COVID19-related deaths or which provided less government economic support during the pandemic did not appear to have higher numbers of requests to WoW (table 2). We did, however, observe a relationship between higher numbers of requests and both the location of abortion service provision and the severity of domestic and international travel restrictions (table 2). In Italy, Portugal and Hungary, all of which showed significant increases in requests to $\mathrm{WoW}$, abortion is provided mostly in the hospital setting and all enacted stringent stay-at-home requirements. In Northern Ireland and
Malta, where significant increases in requests were also observed, in-clinic abortion services are only available by travelling outside of the country, and international travel was restricted during the study periods. In Germany and the Netherlands, we observed no increases in requests, abortion services remained available in clinic settings and no countrywide domestic travel restrictions were enacted. In Great Britain, abortion services were made available by fully remote telemedicine shortly after lockdown began and we observed a significant decrease in requests.

\section{DISCUSSION}

During the first wave of the COVID-19 pandemic in Europe, we observed changes in requests to the WoW online telemedicine abortion service among five out of eight countries in our analysis. Among countries where abortion is legally available within the formal healthcare setting, we observed increased requests in those countries that had more stringent stay-at-home requirements-including countrywide domestic travel restrictions-and where abortion is mostly available only in the hospital setting. Among the two countries where abortion was not legally available within the formal healthcare setting during the study period and where travel outside the country was restricted, we also observed an increase in requests. Among countries where abortion is legally available but which enacted less stringent stay-at-home policies (including no countrywide domestic travel restrictions) and where abortions are provided outside the hospital setting, we observed no increases in requests. In the sole country where abortion services were made available by fully remote telemedicine during the study period, we observed a significant decrease in requests.

Our data provide a unique window into requests for self-managed medication abortion using online telemedicine during the COVID-19 pandemic. Key strengths include the ability to measure changes in demand for self-managed abortion without relying on self-reporting and the ability to compare data

\begin{tabular}{llclll}
\hline Table 1 & Actual versus expected numbers of self-managed abortion requests in the 'after' period for each country included in the study \\
\hline Country & $\begin{array}{l}\text { Actual requests, } \\
\text { before period }\end{array}$ & $\begin{array}{l}\text { Actual requests, } \\
\text { after period }\end{array}$ & $\begin{array}{l}\text { Expected } \\
\text { requests, after } \\
\text { period }\end{array}$ & $\begin{array}{l}\text { Percent change over } \\
\text { baseline trend } \\
\text { (95\% Cl) }\end{array}$ & P value \\
\hline Portugal & 11 & 34 & 14.2 & $139.0(54.5$ to 385.7$)$ & $<0.001$ \\
\hline Italy & 603 & 53 & 31.6 & $67.9(23.3$ to 152.4$)$ & $<0.001$ \\
\hline Hungary & 279 & 113 & 83.2 & $35.8(11.9$ to 71.2$)$ & $<0.001$ \\
\hline Malta & 162 & 69 & 52.3 & $31.9(3.0$ to 76.9$)$ & $<0.001$ \\
\hline Northern Ireland (UK) & 984 & 97 & 75.8 & $28.0(4.3$ to 64.4$)$ & 0.001 \\
\hline Germany & 620 & 465 & 467.1 & $-0.5(-9.0$ to 9.2$)$ & 0.798 \\
\hline The Netherlands & 317 & 47 & 50.9 & $-7.7(-28.8$ to 27.0$)$ & 0.458 \\
\hline Great Britain & 60 & 1 & 8.1 & $-87.6(-92.9$ to -66.7) & $<0.001$ \\
\hline
\end{tabular}




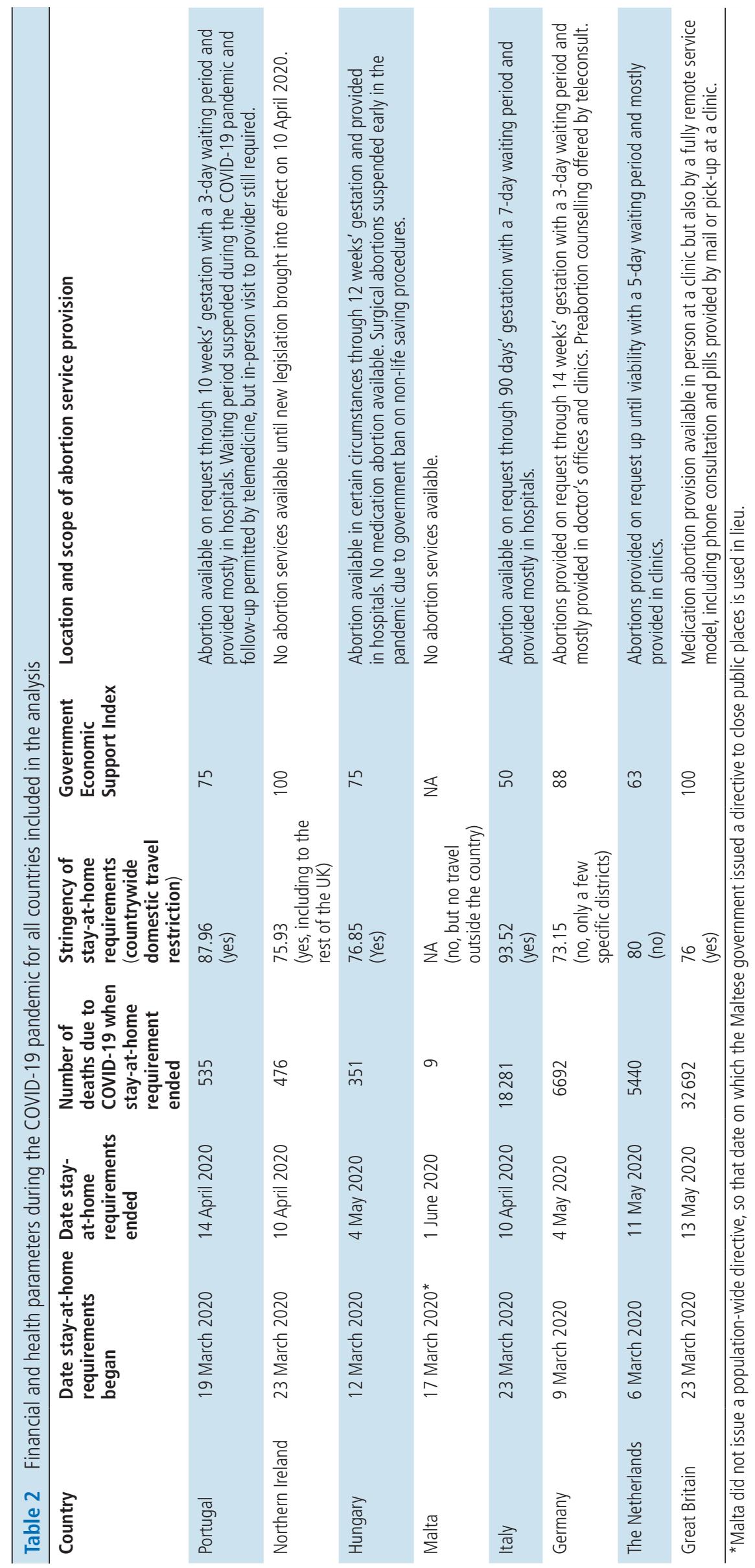


from before and after the emergence of COVID-19. An important limitation, however, is that there are other pathways to abortion outside the formal healthcare setting in Europe, including alternative sources of mifepristone and misoprostol and non-medication methods, such as botanicals. Thus, we cannot measure all demands for self-managed abortion during the pandemic. In addition, the quasi-experimental design of our study lends itself to examining associations rather than formally establishing causal links. We also lack nuanced insight into the reasons underlying changes in requests to WoW for any particular country. In the two countries where we observed no increases in requests, people likely still encountered challenges to accessing abortion. ${ }^{23}$ Future qualitative work could address this knowledge gap, as well as explore people's preferences for how and where to access abortion care.

Our results may reflect two distinct phenomena. First, in some countries, more people may be seeking abortion through all available channels during the pandemic. The decision to end a pregnancy could be due to the perception of risk posed by COVID19 , reduced access to prenatal care or limited social support during lockdowns. ${ }^{24}$ Additionally, decisionmaking could be influenced by the economic downturn COVID-19 has precipitated. ${ }^{25}$ Social distancing policies may also increase rates of unintended pregnancy due to increased time spent at home with a partner or reduced access to contraception. ${ }^{26}$

Second, the observed increases in requests may represent a shift in demand from in-clinic abortion to self-managed abortion using online telemedicine. In countries where abortion services are provided predominantly or solely in hospital settings, people may have feared entering a hospital due to perceived or real risk of infection. Even where limited alternatives are available in the community setting, accessing these services may still have been extremely challenging due to the infection risk associated with public transport, inability to escape surveillance from a controlling partner or difficulty finding childcare. Moreover, in countries with no abortion services, the inability to travel abroad to seek abortion care due to travel restrictions may have led more people to seek an alternative in online telemedicine. Indeed, our findings from Northern Ireland show a steep increase in requests to WoW following the introduction of lockdown measures, followed by a levelling off shortly after the introduction of within-country abortion services. We do not necessarily interpret this pattern as an indication of the immediate availability of abortion services in Northern Ireland, since people living there may have been responding to the authorisation of services only to find that nothing had yet become available or that new services were very limited in scope. Additionally, BPAS made a pills by post service available in Northern Ireland, which could also account for some of the decline in requests to WoW.
People in countries where the challenges to accessing medication abortion are greatest found their own solutions outside the clinic setting during the COVID-19 pandemic. However, while self-managed medication abortion provided via online telemedicine is a safe and effective option, ${ }^{11} 12$ it is not without legal risks. ${ }^{27}$ Its safety also depends on access to the formal healthcare system when necessary, which is not guaranteed during a pandemic. Additionally, while some people may prefer self-managed medication abortion, others may experience it as fraught and isolating due to stigma or the threat of criminalisation and may prefer in-clinic care. ${ }^{28}$ Despite the fact that the WHO recommends the use of telemedicine abortion provision models during the COVID-19 pandemic, ${ }^{29}$ only Great Britain responded to pandemic by purposefully changing their medication abortion service to circumvent the difficulties of in-person care. Following the introduction of a fully remote no-test telemedicine service for medication abortion up to 10 weeks' gestation, requests to WoW decreased to a single consultation. This dramatic decrease points not only to the removal of access barriers posed by COVID-19, but also of pre-existing barriers. Evidence from other settings suggests that similar telemedicine models for medication abortion are safe, effective and acceptable to patients. ${ }^{30}$

\section{CONCLUSION}

Our findings provide evidence in support of the need for service model changes to make medication abortion more accessible during and beyond the COVID-19 pandemic. Fully remote no-test provision of early medication abortion negates the need to visit a hospital or healthcare facility, thus preserving personal protective equipment and reducing infection risks for both patients and healthcare providers. Follow-up care can be provided in the clinic if necessary, and patients have clear continuity of care in the rare instances in which adverse events occur. Authorising and implementing telemedicine models within the formal healthcare setting in line with the WHO recommendations would help to meet the demand we observed for remote provision and would ensure truly patient-centred care.

Contributors ARAA and CA conceived of the original research question. ARAA, CA, JGS and JS contributed to the study design. RG provided the deidentified data. JS conducted the statistical analyses and prepared the tables and figures. ARAA and CA did the initial data interpretation. ARAA wrote the first draft of the manuscript. All authors contributed to final data interpretation, revised first and subsequent drafts critically for intellectual content and approved the final manuscript. All authors agree to be accountable for all aspects of the work. ARAA is the manuscript's guarantor.

Funding This study was supported in part by the Eunice Kennedy Shriver National Institute of Child Health \& Human Development of the National Institutes of Health (NIH) through Center Grant P2CHD042849, awarded to the Population Research Center at The University of Texas at Austin. The funder played no role in the study design; in the collection, analysis and interpretation of data; in the 
writing of the report or in the decision to submit the article for publication. The authors are completely independent from the funding sources. The content of this article is solely the responsibility of the authors and does not necessarily represent the official views of the NIH.

Disclaimer We plan to disseminate the results to people who have made requests to the Women on Web (WoW) service by having a link to the published paper included in the 'Research' section of the WoW website.

Competing interests All authors have completed the ICMJE uniform disclosure form at www.icmje.org/coi_disclosure.pdf and declare: ARAA and JS have received grant support from the Society of Family Planning and infrastructure support from the National Institutes of Health. The authors declare no financial relationships with any organisations that might have an interest in the submitted work in the previous 3 years. RG is the founder and director of Women on Web. The authors declare no other relationships or activities that could appear to have influenced the submitted work.

Patient and public involvement Patients and/or the public were not involved in the design, or conduct, or reporting, or dissemination plans of this research.

Patient consent for publication Not required.

Ethics approval The Institutional Review Board at The University of Texas at Austin reviewed the study protocol and declared the use of precollected, fully deidentified data exempt from the need for approval.

Provenance and peer review Not commissioned; externally peer reviewed.

Data availability statement No additional data are available. All authors, external and internal, had full access to all of the data (including statistical reports and tables) in the study and can take responsibility for the integrity of the data and the accuracy of the data analysis.

This article is made freely available for use in accordance with BMJ's website terms and conditions for the duration of the covid-19 pandemic or until otherwise determined by BMJ. You may use, download and print the article for any lawful, noncommercial purpose (including text and data mining) provided that all copyright notices and trade marks are retained.

\section{ORCID iD}

Abigail R A Aiken http://orcid.org/0000-0002-1555-3025

\section{REFERENCES}

1 Council on Foreign Relations. Women Around the World \& Women and Foreign Policy Program. Abortion in the Time of COVID-19, 2020. Available: https://www.cfr.org/blog/ abortion-time-covid-19 [Accessed 4 Sep 2020].

2 European Parliamentary Forum for Sexual and Reproductive Rights \& International Planned Parenthood Federation Report Women and girls left without care: a snapshot in time during COVID-19, 2020. Available: https://www.epfweb.org/sites/ default/files/2020-05/epf_-_ipff_en_joint_report_sexual_and_ reproductive_health_during_the_covid-19_pandemic_23.04. 2020.pdf [Accessed 4 Sep 2020].

3 Department of Health and Social Care. Temporary approval of home use for both stages of early medical abortion in England, 2020. Available: https://www.gov.uk/government/publications/ temporary-approval-of-home-use-for-both-stages-of-earlymedical-abortion-2 [Accessed 4 Sep 2020].

4 Department of Health and Social Services. Temporary approval of home use for both stages of early medical abortion in Wales, 2020. Available: https:/gov.wales/temporary-approval-homeuse-both-stages-early-medical-abortion [Accessed 4 Sep 2002].
5 Scottish Government Chief Medical Officer Directorate. Temporary approval of home use for both stages of early medical abortion in Scotland, 2020. Available: https://www. sehd.scot.nhs.uk/cmo/CMO(2020)09.pdf [Accessed 4 Sep 2020].

6 Santé Haute Authorité de. Réponses rapides dans le cadre du COVID-19 - Interruption Volontaire de Grossesse (IVG) médicamenteuse à la 8ème et à la 9ème semaine d'aménorrhée (SA) hors milieu hospitalier, 2020. Available: https://www.has-sante.fr/upload/docs/application/pdf/202004/reponse_rapide_ivg_09_04_2020_coiv8.pdf [Accessed 4 Sep 2020].

7 Webber M. How coronavirus is changing access to abortion. Politico, 2020. Available: https://www.politico.eu/article/ how-coronavirus-is-changing-access-to-reproductive-health/ [Accessed 4 Sep 2020].

8 Moreau C, Shankar M, Glasier A, et al. Abortion regulation in Europe in the era of COVID-19: a spectrum of policy responses. BMJ Sex Reprod Health 2020. doi:10.1136/ bmjsrh-2020-200724. [Epub ahead of print: 22 Oct 2020].

9 Center for Reproductive Rights. European governments must ensure safe and timely access to abortion care during the COVID-19 pandemic. Available: https://reproductiverights. org/press-room/european-governments-must-ensure-safe-andtimely-access-abortion-care-during-covid-19 [Accessed 4 Sep 2020].

10 Marie Stopes International. COVID-19 threatens women's health, 2020. Available: https://mariestopes-us.org/2020/covid19-threatens-womens-health/ [Accessed 4 Sep 2020].

11 Gomperts RJ, Jelinska K, Davies S, et al. Using telemedicine for termination of pregnancy with mifepristone and misoprostol in settings where there is no access to safe services. BJOG 2008;115:1171-8.

12 Aiken ARA, Digol I, Trussell J, et al. Self reported outcomes and adverse events after medical abortion through online telemedicine: population based study in the Republic of Ireland and Northern Ireland. BMJ 2017;357:j2011.

13 Women on web. Available: https://www.womenonweb.org/en/ page/521/about-women-on-web [Accessed 4 Sep 2020].

14 Women on Web. Spain censors information about abortion amid Covid-19 lockdown, 2020. Available: https://www. womenonweb.org/en/page/20230/spain-censors-informationabout-abortion-amid-covid-19-lockdown [Accessed 4 Sep 2020].

15 Venkataramani AS, Bor J, Jena AB. Regression discontinuity designs in healthcare research. BMJ 2016;352:11216.

16 Azzopardi K. Covid-19 regulations repealed, vulnerable people no longer required to stay at home. Malta Independent, 2020. Available: https://www.independent.com.mt/articles/202006-04/local-news/Covid-19-regulations-repealed-vulnerablepeople-no-longer-required-to-stay-at-home-6736223847 [Accessed 4 Sep 2020].

17 Ferguson A. Northern Ireland authorities give green light to abortion services. Reuters, 2020. Available: https://www. reuters.com/article/us-britain-nireland-abortion/northernireland-authorities-give-green-light-to-abortion-servicesidUSKCN21R2XG [Accessed 4 Sep 2020].

18 University of Oxford Blavatnik School of Government. Coronavirus government response Tracker. Available: https:// www.bsg.ox.ac.uk/research/research-projects/coronavirusgovernment-response-tracker [Accessed 4 Sep 2020].

19 Europe abortion access project. Available: https://europeaborti onaccessproject.org [Accessed 4 Sep 2020]. 
20 Bellizzi S, Ronzoni AR, Pichierri G, et al. Safe abortion amid the COVID-19 pandemic: the case of Italy. Int J Gynecol Obstet 2020;150:254-5.

21 Caruana-Finkel L. Abortion in the time of COVID-19: perspectives from Malta. Sex Reprod Health Matters 2020;28:1780679.

$22 \mathrm{R}$ Core Team. R: a language and environment for statistical computing. Vienna, Austria: R Foundation for Statistical Computing, 2017. https://www.R-project.org/

23 Stevis-Gridneff M, Haridasani Gupta A, Pronczuk M. Coronavirus created an obstacle course for safe abortions. the new York times. Available: https://www.nytimes.com/2020/ 06/14/world/europe/coronavirus-abortion-obstacles.html [Accessed 4 Sep 2020].

24 Bayefsky MJ, Bartz D, Watson KL. Abortion during the Covid-19 Pandemic - Ensuring Access to an Essential Health Service. N Engl J Med 2020;382:e47.

25 Alderman L, Stevis-Gridneff M. The Pandemic's Economic Damage Is Growing. The New York Times, 2020. Available: https://www.nytimes.com/2020/07/07/business/EU-OECDcoronavirus-economic-reports.html [Accessed 4 Sep 2020].
26 UNFPA. With contributions from Avenir health, Johns Hopkins University (USA) and Victoria university (Australia). impact of the COVID-19 pandemic on family planning and ending gender-based violence, female genital mutilation and child marriage, 2020. Available: https://www.unfpa.org/ resources/impact-covid-19-pandemic-family-planning-andending-gender-based-violence-female-genital [Accessed 4 Sep 2020].

27 Hervey T, Sheldon S. Abortion by telemedicine in the European Union. Int J Gynaecol Obstet 2019;145:125-8.

28 Aiken ARA, Johnson DM, Broussard K, et al. Experiences of women in Ireland who accessed abortion by travelling abroad or by using abortion medication at home: a qualitative study. BMJ Sex Reprod Health 2018;44:181-6.

29 World Health Organization (WHO). Maintaining essential health services: operational guidance for the COVID-19 context, 2020. Available: https://apps.who.int/iris/handle/ 10665/332240 [Accessed 4 Sep 2020].

30 Kohn JE, Snow JL, Simons HR, et al. Medication abortion provided through telemedicine in four U.S. states. Obstet Gynecol 2019;134:343-50. 